\title{
DISAIN PISAU SADAP MANUAL UNTUK MENGOPTIMALKAN PRODUKSI TANAMAN KARET (HEVEA BRASILIENSIS)
}

\author{
Manual Tapping Knife Design to Optimize the Yield of Rubber Trees \\ (Hevea brasiliensis) \\ Suhermanto Agung WIBOWO \\ Balai Penelitian Sungei Putih, Pusat Penelitian Karet \\ Sungei Putih, Deli Serdang, Sumatera Utara \\ PO BOX 1415 Medan 20001 \\ Email: agung_saw@yahoo.com
}

Diterima : 31 Januari 2018 / Disetujui : 19 Februari 2018

\begin{abstract}
Tapping knife which is generally used in rubber estate is currently not be standarized. The quality of tapping knife is determined by the proper selection of metal materials and the dimension of the tapping knife that suit to the tapper body's. The research conducted to study the ideal criteria of the tapping knife by applying direct observation and measurement at PT. Perkebunan Nusantara Management - Java and Sumatera Areas. The result informed that factors affecting the selection of tapping knife was the blade should be sharp and easily sharpen (could last for 2-3 usage), weight about 120 -190 g, hand grips suitable to tapper, the shape of groove angle and binder between iron stalk and handle must be strong. The angle of the blade that formed tapping groove was around 45-50 degrees for plants that newly opened for tapping and 60 degrees for young plants. Other requirements of the ideal tapping knife design included the length of the stalk was suitable to the height of the tapping panel and tapper body, and the thickness of the iron handle should be at least as $2 \mathrm{~mm}$ in order to avoid vibration during tapping.
\end{abstract}

Keywords : Anthropometry; tapper; tapping knife; yield of rubber tress

\section{Abstrak}

Pisau sadap untuk eksploitasi tanaman karet yang digunakan di perkebunan karet di Indonesia belum dilakukan standarisasi secara nasional. Kualitas pisau sadap ditentukan dengan pemilihan material logam yang tepat dan dimensi pisau sadap yang sesuai dengan penyadap. Hasil pengamatan di berbagai wilayah perkebunan karet memperlihatkan bahwa pisau sadap memiliki bentuk, dimensi dan material yang sangat bervariasi. Penelitian ini mempelajari kriteria ideal pisau sadap manual yang dapat digunakan oleh penyadap di seluruh perkebunan karet. Penelitian dilakukan dengan metode survei melalui pengamatan dan pengukuran langsung di beberapa Kebun dalam Lingkup PT. Perkebunan Nusantara yang beroperasi di Wilayah Jawa dan Sumatera. Berdasarkan hasil pengamatan diketahui bahwa faktor utama yang menjadi pertimbangan pemilihan pisau sadap oleh penyadap adalah pisau sadap dapat diasah, berat 120-190 g, ketajaman bertahan 2-3 kali pemakaian (3 ancak), genggaman tangan sesuai penyadap, bentuk sudut paritan dan pengikat antara tangkai besi dan gagang harus kuat. Dari hasil penelitian ini juga diperoleh bahwa sudut mata pisau yang membentuk alur atau paritan sadap sekitar 45-50 derajat untuk tanaman yang baru buka sadap dan 60 derajat untuk tanaman muda. Persyaratan lain disain pisau sadap yang ideal antara lain panjang tangkai sesuai dengan tinggi panel sadap dan tinggi postur tubuh penyadap, serta tebal gagang besi minimal $2 \mathrm{~mm}$ agar tidak terjadi getaran atau fibrasi pada saat menyadap.

Kata kunci : Antropometri; penyadap; pisau sadap; produksi karet alam 


\section{PENDAHULUAN}

Peralatan sadap yang meliputi pisau sadap, talang getah, mangkok sadap merupakan sarana dalam upaya menggali produksi tanaman untuk memperoleh getah (Riawan, Sayamar, \& Kausar, 2015). Tanaman karet Hevea brasiliensis Muell Arg mengeluarkan getah yang berwarna putih seperti susu setelah jaringan kulit diiris hingga mendekati kambium (Afiq \& Azura, 2013). Getah tanaman karet dikenal dengan sebutan lateks (Purbaya, Sari, Saputri \& Fajriaty, 2011). Sedangkan alat yang digunakan untuk mengiris jaringan kulit tanaman karet adalah pisau sadap (Ulfah et al., 2015; Zohrah et al., 2016). Pemilihan pisau sadap yang tepat perlu memperhatikan beberapa faktor antara lain disesuaikan dengan umur tanaman, ketinggian panel sadap dan tebal tipisnya kulit. Penggalian produksi yang optimal turut dipengaruhi oleh keterampilan penyadap. Keterampilan penyadap diukur berdasarkan kemampuannya dalam mengendalikan konsumsi kulit per hari sadap serta kedalaman sadapan yang tidak sampai merusak jaringan kayu batang tanaman karet (Susanto \& Hanif, 2017).

Pisau sadap manual tanaman karet yang digunakan di perkebunan karet di Indonesia hingga saat ini belum dilakukan standarisasi secara nasional. Padahal standarisasi produk pisau sadap akan sangat menentukan kualitas pisau sadap tersebut (Harjadi, 1986). Pisau sadap berkualitas unggul akan memberikan hasil irisan pohon karet yang baik dan diikuti dengan produksi lateks yang optimal. Kualitas produk pisau sadap ditentukan antara lain oleh pemilihan material logam pisau sadap, serta bentuk dan dimensi pisau sadap. Material logam pisau sadap manual komersial yang telah beredar di pasaran sangat bervariasi, tergantung ketersediaan di daerah penghasil atau pabrikan pisau sadap tersebut. Selanjutnya faktor bentuk dan dimensi pisau sadap sangat dipengaruhi oleh subyektivitas penyadap. Penyadap cenderung membuat sendiri pisau sadap yang akan digunakannya di pengrajin logam (pandai besi) atau dengan memodifikasi mata pisau sadap manual yang telah didistribusikan oleh pihak Manajemen Perkebunan Karet. Pisau sadap manual yang diproduksi secara massal oleh pabrikan belum memenuhi standar untuk dapat langsung dipergunakan untuk menyadap pohon karet. Hal ini dikarenakan pisau sadap tersebut tidak sesuai dengan agroteknis daerah tertentu. Sebagai contoh tanaman karet di daerah Jawa didominasi oleh tanaman karet dengan jenis klon yang mempunyai kulit tebal, batang besar dan produksi ke belakang semakin tinggi (slow starter). Sedangkan di daerah Sumatera didominasi oleh tanaman karet klon baru dengan kulit cukup tebal, pohon tidak besar dan produksi di awal yang tinggi (quick starter) (Andriyanto \& Tistama, 2014).

Pisau sadap manual pada awalnya merupakan pisau berbentuk $\mathrm{U}$, dengan bagian yang tajam terletak pada ujung bilah pisau dan ditekuk membentuk sudut tertentu (Kochhar, 2016). Dalam perkembangannya, bagian mata pisau yang tajam terletak di depan dan belakang atau dikenal dengan mata pisau dua arah. Selanjutnya, pada tahun 1984 mulai dilakukan upaya mekanisasi penyadapan pohon karet di Malaysia. Salah satu contoh pisau sadap mekanis yang telah dikomersialkan adalah Pisau Sadap Motoray (Sail \& Muhamad, 1994) yang ditunjukkan pada Gambar 1. Pisau sadap Motoray digerakkan dengan motor listrik menggunakan baterai. Motor listrik yang digunakan mempunyai kecepatan putar $3000 \mathrm{rpm}$ dengan baterai yang dapat diisi ulang bertegangan 12 Volt. Ketika digunakan untuk melakukan penyadapan pohon karet, baterai diikatkan di pinggang panyadap. Pisau sadap Motoray menerapkan sistem pengirisan kulit pohon karet dengan sistem getar. Penyadap mengoperasikan pisau sadap tersebut dengan mengarahkan mata pisau pada alur sadapan. Penggunaan pisau sadap tipe ini masih memiliki kelemahan yaitu konsumsi kulit yang boros atau tebal, sudut mata pisau tidak sesuai untuk tanaman muda dan daya baterai (listrik) tidak bertahan lama.

Pisau sadap manual masih tetap menjadi pilihan utama sarana penyadapan pohon karet. Gambar 2 memperlihatkan salah satu contoh pisau sadap manual standar yang hanya digunakan di salah satu perkebunan di Sumatera Utara untuk buka sadap pada umur tanaman 5 tahun. Pisau sadap manual tersebut memiliki spesifikasi panjang $20-25 \mathrm{~cm}$ dengan panjang tangkai $13 \mathrm{~cm}$, bilah pisau memiliki lebar $2-2,5 \mathrm{~cm}$ 


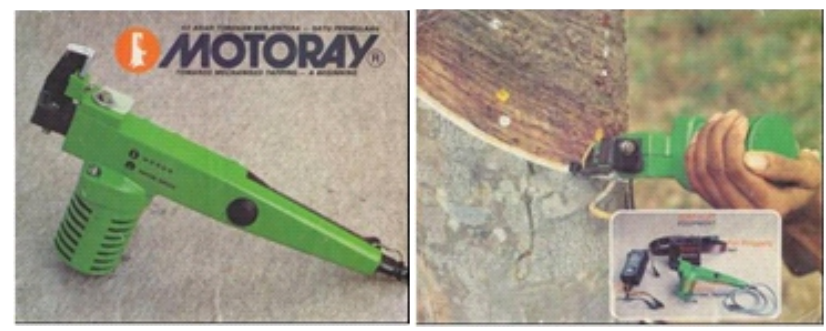

Gambar 1. Pisau sadap mekanis Motoray dan pengoperasiannya Figure 1. Mechanical tapping knife "Motoray" and its operational

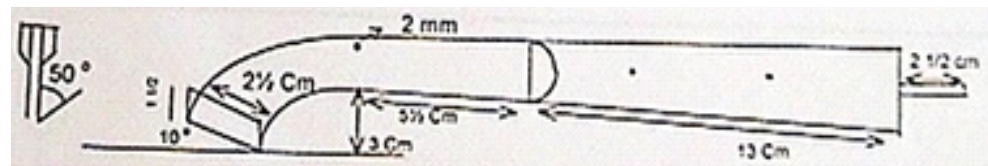

Gambar 2. Pisau sadap manual digunakan di Perkebunan Sumatera Utara Figure 2. Manual tapping knife is used in North Sumatera Rubber Estate

dan tebal $2-3 \mathrm{~mm}$, sudut paritan 50 derajat dan sudut ujung pisau terhadap garis horizontal sebesar 10 derajat. Pada ujung gagang pisau terdapat paku $2,5 \mathrm{~cm}$ yang dimaksudkan agar pada waktu membuka alur sadap tidak dilakukan dengan mendorong pisau menggunakan tekanan telapak tangan sehingga batas bidang sadap bagian depan tetap lurus. Penggunaan bentuk pisau sadap ini hanya berlaku selama 2 tahun pertama dan kemudian pisau sadap berubah pada sudut paritan 60 derajat, sudut ujung pisau terhadap garis horisontal menjadi 20 derajat dan tinggi ujung mata pisau terhadap garis horisontal bertambah menjadi $4 \mathrm{~cm}$ serta gagang bertambah $5 \mathrm{~cm}$.

Upaya yang dilakukan dalam merumuskan pisau sadap yang berstandar nasional yaitu pengumpulan beberapa pisau sadap manual dari berbagai perkebunan karet di Indonesia, menguji efektivitas fungsinya, penerimaan penyadap dan membandingkannya. Kegiatan penelitian ini mempelajari tentang kualitas pisau sadap manual dari segi dimensi, bentuk, material dan antropometri penyadap.

\section{BAHAN DAN METODE}

Penelitian pengujian lima pisau sadap manual dilakukan pada tahun 2011 2012 di Kebun Percobaan Balai Penelitian Sungei Putih, Kabupaten Deli Serdang,
Sumatera Utara. Alat utama yang dipergunakan dalam penelitian ini yaitu lima contoh pisau sadap manual (pisau 1 representasi dari perkebunan swasta di Sumatera Utara, pisau 2 representasi dari salah satu PT. Perkebunan Nusantara di Sumatera Utara, Pisau 3 dan 4 representasi dari salah satu PT. Perkebunan Nusantara di Kalimantan Timur, Pisau 5 representasi dari perkebunan rakyat di Sumatera Utara), mistar, meteran gulung, alat ukur ketebalan kulit, busur, gelas ukur, ember, kursi, papan, meteran logam, akrilik siku, timbangan badan, seng gulung diklem, jangka sorong digital dan kamera. Adapun tanaman karet untuk sampel uji yang digunakan adalah tanaman karet klon PB 260 Tahun Tanam 2003 sebanyak 5 ancak. Selain itu juga ditetapkan beberapa kondisi pengujian meliputi tinggi panel sadap di panel bawah $(<150 \mathrm{~cm})$, panjang irisan $1 / 2$ Spiral dan $1 / 4$ Spiral, sudut irisan 40 hingga 30 derajat terhadap garis horizontal (50 hingga 60 derajat terhadap vertikal).

Metode penelitian dilakukan dengan pengukuran dimensi pisau sadap manual, pengujian lapangan, pengukuran antropometri sampel 10 orang penyadap dan analisis gerak proses penyadapan. Pada pengujian sadapan di lapangan mengacu pada parameter lilit batang, tebal kulit, panjang alur sadap, kedalaman sadapan, serta konsumsi kulit per sadap tanaman karet. Pengukuran antropometeri adalah pengukuran untuk mengetahui ukuran fisik seseorang dengan menggunakan alat ukur 
tertentu misal timbangan badan dan pita ukur (meteran) (Moreno et al., 2003; Pheasant \& Haslegrave, 2005). Pengukuran antropometeri penyadap difokuskan pada komponen tubuh penyadap yang berkaitan langsung dengan posisi pada saat dilakukan penyadapan.

\section{Rancang Bangun Pisau Sadap Manual}

Pisau sadap manual berfungsi untuk mengiris jaringan kulit (pembuluh lateks) pada batang tanaman karet dari arah kiri atas ke kanan bawah dengan sudut kemiringan 30 hingga 40 derajat pada sadap ke arah bawah dan 45 hingga 50 derajat pada sadapan ke arah atas. Bagian pisau sadap manual terdiri dari mata pisau, leher pisau, dan gagang. Bagian mata pisau hingga leher pisau dibuat menggunakan material besi dan gagang pada umumnya dibuat menggunakan material kayu. Bagian leher pisau terdapat lubang yang difungsikan untuk membengkokan kawat mangkok sadap. Bagian mata pisau yang tajam terdapat pada sisi belakang untuk pisau sadap tarik atau sisi depan untuk pisau sadap sorong. Ketajaman mata pisau terdapat pada kedua sisinya, yang digunakan untuk sadap tarik dan sadap sorong pada ketinggian panel di bawah 150 $\mathrm{cm}$. Ketinggian panel di atas $150 \mathrm{~cm}$ digunakan pisau sadap pacekung dan dioperasikan dengan cara menyorong.

\section{HASIL DAN PEMBAHASAN}

\section{Dimensi dan Bentuk Pisau Sadap Manual}

Pisau sadap manual yang diuji merupakan pisau sadap manual yang berasal dari berbagai kebun diambil sebagai contoh uji pada penelitian ini. Pisau-pisau sadap manual tersebut dibuat oleh pengrajin logam (pandai besi) yang berlokasi di sekitar kebun. Berdasarkan pengamatan awal, terlihat bahwa dimensi, bentuk dan material logam yang digunakan dalam pembuatan pisau sadap manual tersebut cukup bervariasi sebagaimana ditunjukkan pada Gambar 3 sebagai berikut.

Gambar 3 memperlihatkan kelima pisau sadap yang diuji di lapangan. Hasil pengujian dimensi pisau sadap secara lengkap disajikan pada Tabel 1. Berdasarkan Tabel 1 terlihat bahwa berat pisau sadap manual antara 120-190 gram. Material gagang secara signifikan menambah berat pisau sadap manual. Gagang pisau sadap tersebut terbuat dari kayu, arnit dan pipa besi. Berdasarkan respon balik dari masing-masing penyadap diketahui bahwa contoh pisau sadap manual nomor 5 yang bergagang besi kurang nyaman digunakan karena terasa licin di tangan dan gagang pisau terlalu pendek. Adapun panjang tangkai besi hingga mata pisau tidak berbeda jauh yaitu antara 9-13 $\mathrm{cm}$. Secara umum dapat diketahui bahwa bentuk pisau sadap manual berbeda pada

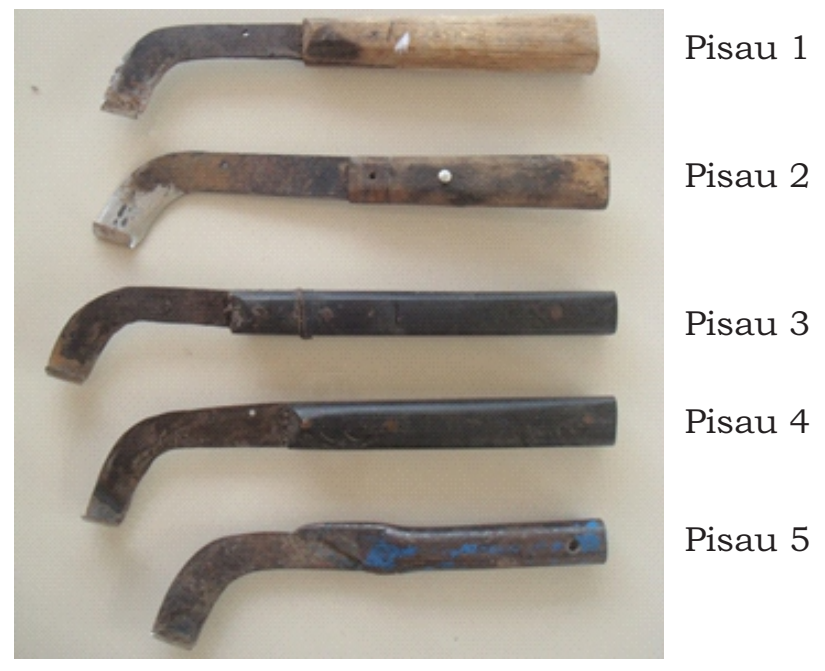

Gambar 3. Berbagai model pisau sadap manual Figure 3. Various model of manual tapping knives 
Tabel 1. Hasil pengukuran dimensi pisau sadap yang diuji Table 1. Measurement of the manual tapping knife dimension

\begin{tabular}{clccccc}
\hline \multirow{2}{*}{ No } & \multirow{2}{*}{$\begin{array}{c}\text { Dimensi pisau sadap manual } \\
\text { Manual tapping knife dimension }\end{array}$} & \multicolumn{5}{c}{ Nomor contoh pisau sadap manual } \\
\cline { 3 - 7 } & & 1 & 2 & 3 & 4 & \multicolumn{3}{c}{ Number of manual tapping } \\
& & 130 & 120 & 190 & 170 & 170 \\
\hline 1 & Berat, g & 3,18 & 2,81 & 2,96 & 3,15 & 2,19 \\
2 & Diagonal gagang, cm & 10,14 & 13,12 & 9,36 & 10,21 & 10,63 \\
3 & Panjang tangkai besi, cm & 0,35 & 0,24 & 0,31 & 0,25 & 0,19 \\
4 & Tebal tangkai besi, cm & 1,95 & 2,34 & 1,89 & 2,59 & 1,95 \\
5 & Tinggi tangki besi, cm & 15,98 & 13,62 & 20,00 & 16,87 & 12,47 \\
6 & Panjang gagang, cm & 2,48 & 1,91 & 2,62 & 2,62 & 1,86 \\
7 & Tebal gagang, cm & 3,19 & 2,89 & 2,31 & 2,62 & 2,32 \\
8 & Tinggi gagang, cm & 26,12 & 26,74 & 29,36 & 27,08 & 23,10 \\
9 & Panjang gagang hingga tangkai, cm & 2,21 & 2,32 & 2,05 & 1,96 & 2,17 \\
10 & Panjang mata pisau, cm & 1,58 & 1,22 & 1,43 & 1,44 & 1,69 \\
11 & Lebar mata pisau, cm & 0,10 & 0,11 & 0,11 & 0,13 & 0,13 \\
12 & Tebal pisau, cm & 60 & 60 & 60 & 60 & 50 \\
13 & Sudut bukaan mata, derajat & & & & & \\
\hline
\end{tabular}

lengkung leher pisau, sudut yang terbentuk dari ujung belakang dan ujung depan mata pisau, dan sudut pisau atau yang membentuk paritan sadap. Bilah pisau sekitar mata pisau terlihat lebih lebar dan tipis karena dibuat dengan ditempa setelah logam berpijar serta diasah agar pipih dan tajam.

\section{Pengujian Penyadapan dengan Pisau Sadap Manual di Lapangan}

Tanaman uji pada penelitian ini menggunakan areal tanaman karet klon PB 260 Tahun Tanam 2003 yang merupakan tanaman menghasilkan tahun ke-4. Lokasi pengujian A1, A2, A3, A4 dan A5 dalam hamparan yang sama yang diawasi oleh seorang mandor sadap. Dari hasil pengukuran di lima lokasi pengujian pisau sadap manual diperoleh bahwa lilit batang (LB) rata-rata sebesar $53,64 \mathrm{~cm}$, panjang alur sadap (PAS) rata-rata $34,85 \mathrm{~cm}$ dan tebal kulit (TK) rata-rata 9,45 $\mathrm{cm}$ (Tabel 2).
Sementara sisa kulit dari kambium rata-rata sebesar 1,9 $\mathrm{mm}$ (Tabel 3). Adapun persyaratan sisa kulit berdasarkan norma penyadapan adalah sebesar $1,5 \mathrm{~mm}$. Data yang diperoleh dari kelima pisau sadap manual yang diuji memperlihatkan bahwa konsumsi kulit per sadap sekitar 2,1-2,6 $\mathrm{mm}$. Selanjutnya Pada Tabel 3 memperlihatkan bahwa pisau sadap ke-2 lebih terkendali dalam mengatur ketebalan irisan. Hal ini dimungkinkan karena berat dan lebar mata pisau pada pisau sadap manual nomor 2 telah sesuai.

\section{Tinggi Panel Sadap}

Pisau sadap manual harus sesuai dengan tebal kulit dan tinggi panel sadap. Pisau sadap tarik digunakan hanya di panel bawah $(<150 \mathrm{~cm})$ sedangkan pisau sadap manual untuk panel atas $(>150 \mathrm{~cm})$ pada umumnya menggunakan pisau sadap pacekung. Pada penelitian ini, menerapkan sistem sadap $1 / 2 \mathrm{~S} d / 3$ dan $1 / 4 \mathrm{~S} \uparrow \mathrm{d} / 3$. Oleh

Tabel 2. Hasil pengukuran lilit batang, panjang alur sadap, dan tebal kulit Table 2. Girth, lenght of bark cutting, and bark thickness measurement

\begin{tabular}{ccccc}
\hline No & $\begin{array}{c}\text { Lokasi } \\
\text { Location }\end{array}$ & $\begin{array}{c}\text { Lilit batang } \\
\text { Girth } \\
(\mathrm{cm})\end{array}$ & $\begin{array}{c}\text { Panjang alur sadap } \\
\text { Lenght of bark cutting } \\
(\mathrm{cm})\end{array}$ & $\begin{array}{c}\text { Tebal kulit } \\
\text { Bark thickness } \\
(\mathrm{cm})\end{array}$ \\
\hline 1 & A1 & 61,2 & 36,00 & 9,60 \\
2 & A2 & 53,2 & 35,20 & 10,00 \\
3 & A3 & 52,5 & 35,60 & 9,20 \\
4 & A4 & 49,2 & 34,50 & 9,25 \\
5 & A5 & 52,1 & 32,98 & 9,20 \\
\hline \multicolumn{2}{r}{ Rata-rata } & 53,64 & 34,86 & 9,45 \\
\hline
\end{tabular}


Tabel 3. Sisa kulit dari kambium dan konsumsi kulit

Table 3. Bark depthness from cambium and bark consumption

\begin{tabular}{|c|c|c|c|c|c|c|c|}
\hline \multirow{2}{*}{ No } & \multirow{2}{*}{$\begin{array}{c}\text { Penyadap } \\
\text { Tapper }\end{array}$} & \multicolumn{6}{|c|}{$\begin{array}{l}\text { Nomor contoh pisau sadap manual } \\
\text { Number of manual tapping knife sample }\end{array}$} \\
\hline & & 1 & 2 & 3 & 4 & 5 & $\begin{array}{l}\text { Rata-rata } \\
\text { Average }\end{array}$ \\
\hline \multicolumn{8}{|c|}{$\begin{array}{l}\text { Sisa kulit dari kambium } \\
\text { Bark depthness from cambium }\end{array}$} \\
\hline 1 & Penyadap 1 & 1,95 & 1,90 & 1,80 & 1,85 & 2,00 & 1,90 \\
\hline 2 & Penyadap 2 & 1,83 & 1,95 & 2,15 & 2,00 & 1,93 & 1,97 \\
\hline 3 & Penyadap 3 & 2,00 & 2,00 & 1,90 & 2,00 & 1,85 & 1,95 \\
\hline & Rata-rata & 1,93 & 1,95 & 1,95 & 1,95 & 1,93 & \\
\hline \multicolumn{8}{|c|}{$\begin{array}{l}\text { Konsumsi kulit } \\
\text { Bark consumption }\end{array}$} \\
\hline 1 & Penyadap 1 & 1,90 & 2,21 & 2,70 & 2,13 & 2,61 & 2,31 \\
\hline 2 & Penyadap 2 & 2,22 & 2,35 & 1,56 & 2,50 & 2,58 & 2,24 \\
\hline 3 & Penyadap 3 & 2,59 & 1,88 & 2,66 & 2,61 & 2,69 & 2,64 \\
\hline & Rata-rata & 2,24 & 2,15 & 2,31 & 2,41 & 2,63 & \\
\hline
\end{tabular}

karena itu, digunakan satu pisau sadap yang dapat berfungsi untuk mengiris dengan tarik dan sorong. Jangkauan untuk panel atas sekitar $20-30 \mathrm{~cm}$.

Kondisi tanaman karet yang tidak seragam matang sadapnya mengakibatkan tinggi sadapan atau buka sadap yang yang bervariasi. Perbedaan tinggi panel sadap juga disebabkan oleh pemindahan panel akibat mati kulit parsial atau total. Gambar 4 dan Gambar 5 menunjukkan bahwa dalam satu ancak terdapat perbedaan tinggi panel sadap. Kendala ini mengakibatkan posisi penyadap akan berbeda-beda untuk setiap pohonnya, posisi tubuh akan menyesuaikan posisi panel sadap dari posisi tegak hingga membungkuk. Semakin tinggi variasi tinggi panel sadap maka semakin memberat beban kerja penyadap. Dalam upaya mendapatkan produksi yang tinggi maka pihak kebun sering kali menerapkan sistem sadap ganda yaitu sistem sadap ke bawah dengan irisan
$1 / 2 \mathrm{~S}$ dan sistem sadap ke arah atas dengan $1 / 4 \mathrm{~S}$. Gambar 4 menunjukkan pisau sadap yang dapat difungsikan untuk menyadap ke arah atas atau sorong sekaligus ke arah bawah atau tarik.

\section{Arah Mata Pisau Untuk Menggali Potensi Produksi Lateks}

Hal yang harus diperhatikan dalam mengoptimalkan potensi produksi tanaman karet yaitu cara mengiris kulit harus terjadi sodokan dengan sisi mata pisau bagian depan yang diperlihatkan pada Gambar 7, sisi mata pisau belakang tepat berhenti pada batas sadap yang diperlihatkan pada Gambar 8, kedalaman irisan dipertahankan hingga $1,5 \mathrm{~mm}$ dari kambium dan pada sadap ke arah atas juga terdapat sodokan mata pisau sisi depan yang diperlihatkan pada Gambar 9. Cara mengiris pada sistem sadap ke arah yang tidak tepat ditunjukkan pada Gambar 10. Pisau sadap seharusnya

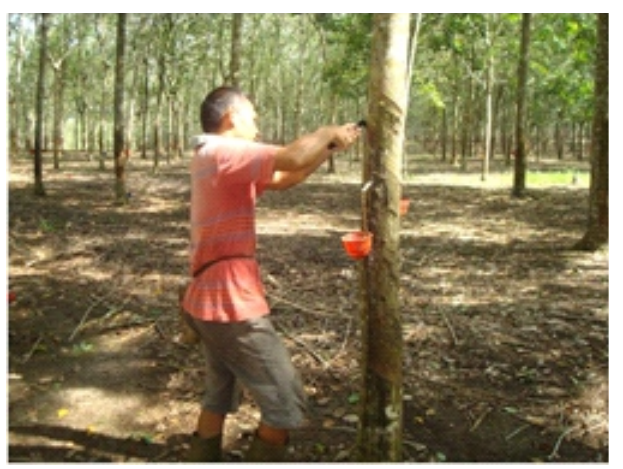

Gambar 4. Penyadapan pada panel BO-1 dan BO-2 tanaman karet Figure 4. Tapping on BO-1 and BO-2 panels of rubber tree 


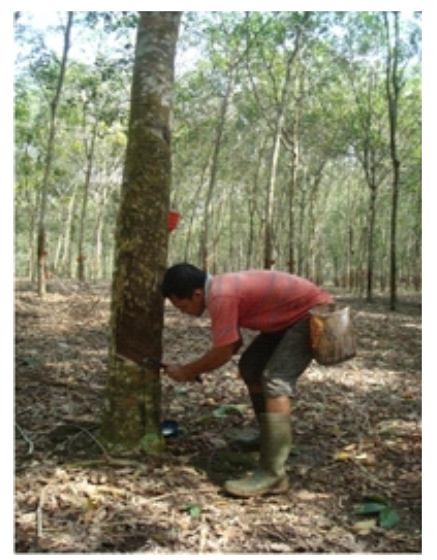

Gambar 5. Penyadapan pada panel BO-1 bawah tanaman karet Figure 5. Tapping on lower BO-1 panel of rubber tree
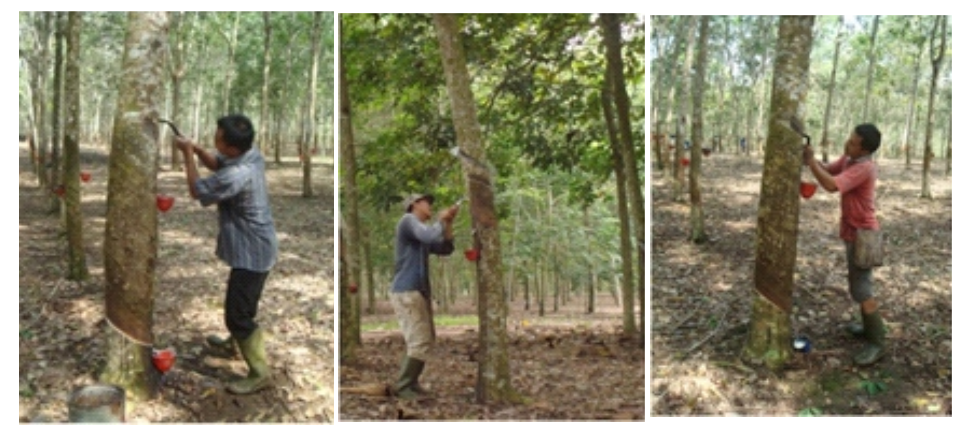

Gambar 6. Penyadapan pada panel HO tanaman karet Figure 6. Tapping on HO panel of rubber tree

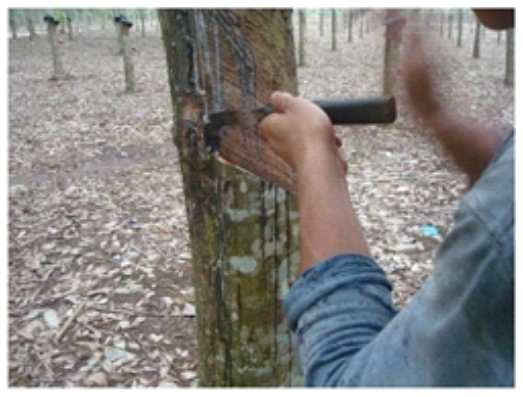

Gambar 7. Sodokan depan mata pisau

Figure 7. Push movement of the manual tapping knife

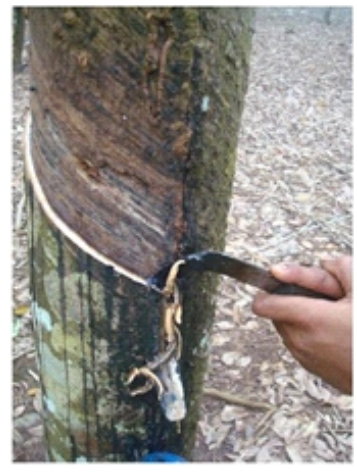

Gambar 8. Batas tarikan mata pisau Figure 8. End cutting downward tapping

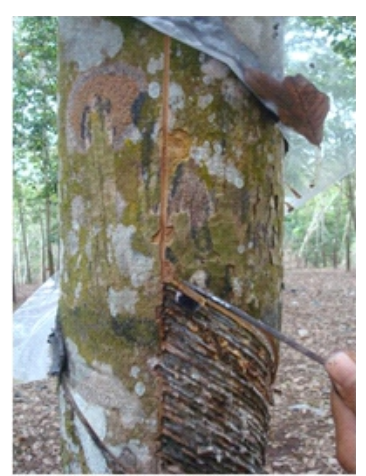

Gambar 9. Sodokan pada sadap ke arah atas Figure 9. End pushing of the upward tapping 

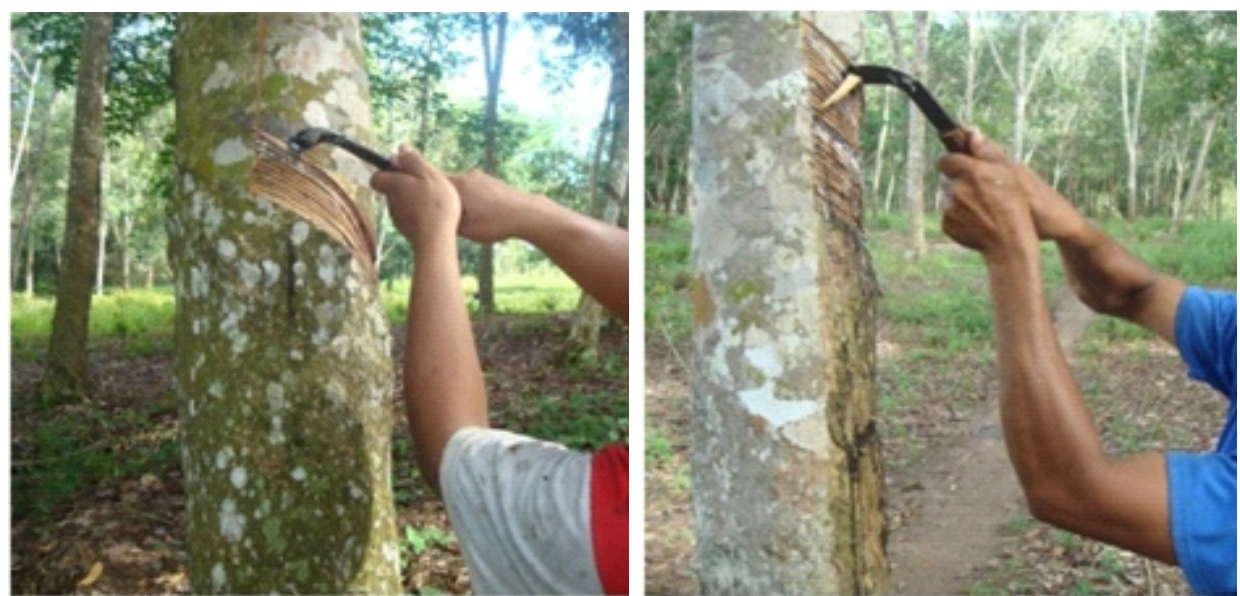

Gambar 10. Sadap ke arah atas yang tidak tepat

Figure 10. Uncorrect upward tapping

digerakkan dengan disorong, bukan ditarik. Akibatnya irisan tersebut tidak menghasilkan tempat sodokan sehingga jumlah atau produksi lateks yang dihasilkan akan lebih sedikit. Bekas parit sadapan ujung atas akan terlihat landai atau dangkal dan konsumsi kulit akan lebih tebal atau boros.

\section{Analisis Antropometri Penyadap}

Penyadap dalam melakukan pekerjaannya tentu akan melakukan gerakan yang sama untuk sekitar 400-500 pohon karet. Gerakan manusia dalam melakukan gerakan kerja memiliki selang alami gerakan tubuh. Gerakan dalam selang alami akan memperlancar sirkulasi darah dan fleksibilitas sehingga gerakan tubuh akan lebih nyaman dan mencapai produktivitas yang lebih tinggi. Selang alami gerakan akan tercapai dengan tidak melakukan gerakan berulang dan ekstrim. Hasil pengukuran terhadap penyadap menunjukkan bahwa pisau sadap akan nyaman dipakai dengan persentil ke-50 (Median) untuk panjang telapak tangan 11,8 $\mathrm{cm}$ dan diameter gagang pisau 4,1 $\mathrm{cm}$ (Tabel 4). Panjang dan diameter gagang pisau sadap yang digunakan berdasarkan antropometri persentil ke-50 dimaksudkan agar penyadap yang memiliki telapak tangan panjang ataupun pendek dan genggaman tangan besar ataupun kecil dapat menggunakannya.

\section{Kriteria Pisau Sadap Manual Yang Baik}

Pisau sadap manual dapat mendukung optimalisasi potensi produksi tanaman karet apabila memenuhi persyaratan disain sebagai berikut:

1. Ketajaman mata pisau mampu bertahan hingga 1.000 pohon (2 ancak).

2. Pisau sadap manual memiliki berat yang ideal bagi penyadap sekitar 120-190 gram sehingga tidak mengakibatkan irisan mengambang ataupun menebal.

Tabel 4. Parameter antropometri yang terkait dengan gerakan menyadap Table 4. Anthropometry parameters that related tapping motion

\begin{tabular}{|c|c|c|c|c|}
\hline \multirow{2}{*}{ No } & \multirow{2}{*}{$\begin{array}{l}\text { Parameter } \\
\text { Paramters }\end{array}$} & \multicolumn{3}{|c|}{$\begin{array}{l}\text { Persentil ke- } \\
\text { Percentile at }\end{array}$} \\
\hline & & 5 & 50 & 95 \\
\hline 1 & Tinggi siku kaki $(\mathrm{cm})$ & 42,01 & 46,60 & 51,19 \\
\hline 2 & Tinggi pinggul $(\mathrm{cm})$ & 86,77 & 92,10 & 97,43 \\
\hline 3 & Tinggi bahu $(\mathrm{cm})$ & 130,51 & 136,90 & 143,29 \\
\hline 4 & Tinggi badan $(\mathrm{cm})$ & 153,60 & 162,00 & 170,40 \\
\hline 5 & Panjang lengan $(\mathrm{cm})$ & 52,52 & 57,60 & 62,68 \\
\hline 6 & Panjang lengan atas $(\mathrm{cm})$ & 21,02 & 33,60 & 36,19 \\
\hline 7 & Panjang telapak tangan $(\mathrm{cm})$ & 10,57 & 11,80 & 13,03 \\
\hline 8 & Diameter genggaman tangan $(\mathrm{cm})$ & 3,73 & 4,10 & 4,46 \\
\hline
\end{tabular}


3. Sudut mata pisau yang membentuk alur/paritan sadap sekitar 45-50 derajat untuk tanaman yang baru buka sadap dan 60 derajat untuk tanaman muda.

4. Panjang tangkai sesuai dengan tinggi panel sadap dan tinggi postur penyadap.

5. Tebal gagang besi minimal $2 \mathrm{~mm}$ agar tidak terjadi getaran atau fibrasi pada saat menyadap.

\section{KESIMPULAN}

Kesimpulan yang dapat ditarik berdasarkan hasil penelitian yang telah dilakukan adalah bahwa parameter konsumsi kulit menentukan kualitas pisau sadap yang baik dan terasa nyaman di genggaman penyadap karena dianggap dapat memperpanjang nilai ekonomi dalam satu siklus. Pisau sadap terbaik yang diuji yaitu pisau sadap nomor 2 karena mampu menghasilkan konsumsi kulit per sadap setebal 2,15 mm, diikuti dengan pisau sadap nomor 1 yang memberikan konsumsi kulit per sadap setebal 2,24 $\mathrm{mm}$. Sementara itu komponen pengukuran antropometeri penyadap yang turut menentukan kualitas pisau sadap meliputi tinggi bahu, panjang lengan, tinggi pinggang dan diameter genggaman tangan. Diameter gagang pisau sadap manual sebagai tempat genggaman tangan penyadap yang direkomendasikan untuk persentil ke-50 (Median) sebesar 4,1 $\mathrm{cm}$.

Pada penelitian selanjutnya perlu dilakukan penambahan jumlah pisau sadap manual yang berasal dari berbagai daerah tidak terbatas di Jawa dan Sumatera, parameter pengukuran antropometeri penyadap juga turut diperbanyak yang didukung dengan pengukuran beban kerja dan efektifitas pisau sadap terhadap berbagai tingkat usia penyadap, jenis kelamin, jenis areal dan jenis pisau yang berbeda.

\section{UCAPAN TERIMA KASIH}

Penulis mengucapkan terima kasih kepada Dr. Tumpal HS. Siregar dan Nurhawaty Siagian, MS yang telah memberikan arahan, dukungan dan bantuan dalam pelaksanaan kegiatan penelitian mengenai berbagai pisau sadap manual yang digunakan di berbagai Perkebunan Karet di Indonesia khususnya di Wilayah Jawa dan Sumatera.

\section{DAFTAR PUSTAKA}

Afiq, M.M., \& Azura, A.R. (2013). Effect of sago strach loadings on soil decomposition of natural rubber latex (NRL) composite films mechanical properties. International Biodeterioration \& Biodegradation, 85, $139-149 . \quad \mathrm{D}$ o $\mathrm{i}$ 10.1016/j.ibiod.2013.06.016

Andriyanto, M., \& Tistama, R. (2014). Perkembangan dan upaya pengendalian kering alur sadap (KAS) pada tanaman karet Hevea brasiliensis. Warta Perkaretan, 33(2), 89-102.

Harjadi, H. (1986). Ke arah standarisasi bahan dasar pisau sadap untuk mencapai produksi maksimum. Prosiding Konferensi Nasional Karet 1986. Medan, Indonesia : Balai Penelitian Sungei Putih

Kochhar, S.L. (2016). Economic botani a comprehensive study fifth editon. New Delhi, India : Cambridge University Press

Moreno, L.A., Joyanes, M., Mesana, M.I., Gonzales-Gross, M., Gil, C.M., Sarria, A., Gutierrez, A., Garaulet, M., PerezPrieto, R., Bueno, M., \& Marcos, A. ( 2003 ). Harmonization of anthropometric measurements a multcenter nutrition survey in spanish adolescents. Applied Nutritional Investigation, 19, 481-486. Doi : 10.1016/S0899-9007(03)00040-6

Pheasant, S., \& Haslegrave, C.M. (2005). Bodyspace: Antropometry, ergonomics, and the design of work third edition. Boca Raton, USA: Taylor \& Francis Group.

Purbaya, M., sari, T.I., Saputri, C.A., \& Fajriaty, M.T. (2011). Pengaruh beberapa jenis bahan pengumpal lateks dan hubungannya dengan susut bobot, kadar karet kering, dan plastisitas. Prosiding Seminar Nasional AvoER ke-3. Palembang, Indonesia: Fakultas Teknik Universitas Sriwijaya 
Riawan, A., Sayamar, E., \& Kausar. (2015). Analisis kearifan lokal tanaman karet di Kecamatan Logas Tanah Darat Kabupaten Kuantan Singingi. Jom Faperta, 2(1), 16p.

Sail, R.M., \& Muhamad, M. (1994). Factors associated with non-adoption of technology by rubber smallholders. Pertanika Journal Social Science \& Humaniora, 2(1), 29-41.

Susanto, H., \& Hanif. (2017). Rancang bangun alat bantu sadap karet dengan pengaturan kedalaman, ketebalan dan kemiringan sudut sadap. Prosiding Seminar Nasional Sains dan Teknologi 2017 (p. 1-9). Jakarta, Indonesia: Fakultas Teknik Universitas Muhammadiyah Jakarta
Ulfah, D., Thamrin, G.A.R., \& Natanael, T.W. (2015). Pengaruh waktu penyadapan dan umur tanaman karet terhadap produksi getah (lateks). Jurnal Hutan Tropis, 3(3), 247-252.

Zohrah, P.A., Yusmini., \& Edwina, S. (2016). Analisis kelayakan finansial usaha perkebunan karet program eks UPP TCSDP di Desa Koto Damai Kecamatan Kampar Kiri Tengah Kabupaten Kampar. Jom Faperta, 3(2), 1-10. 